\title{
ANTIOXIDANT ACTIVITY AND OPTIMISATION OF ULTRASONIC-ASSISTED EXTRACTION BY RESPONSE SURFACE METHODOLOGY OF ARONIA MELANOCARPA ANTHOCYANINS
}

\author{
Shanshan Chen, Xianjun Meng*, Yuehua Wang, Xiyun Sun \\ College of Food Science, Shenyang Agricultural University, Shenyang, China \\ *Corresponding Author E-mail: mengxjsy@126.com
}

This is an open access article distributed under the Creative Commons Attribution License, which permits unrestricted use, distribution, and reproduction in any medium, provided the original work is properly cited.

\begin{tabular}{|c|c|}
\hline ARTICLE DETAILS & ABSTRACT \\
\hline Article History: & The Based on one-factor-at-a-time experiments, response surface methodology was employed to optimize \\
\hline Received 12 November 2017 & conditions were determined as follows: ethanol concentration $62 \%$, ultrasonic power $198 \mathrm{~W}$, liquid-solid ratio 19 \\
\hline Accepted 12 December 2017 & $(\mathrm{~mL} / \mathrm{g})$ and ultrasonic time $44 \mathrm{~min}$. Under this condition, AMP anthocyanin yield was $4.31893 \mathrm{mg} / \mathrm{g}$ with a $1.67 \%$ \\
\hline Available online 1 January 2018 & error compared with the actual value, which showed that the model and the optimization process was feasible. \\
\hline & $\begin{array}{l}\text { Additionally, superoxide anion radical }\left(\mathrm{O}^{2-\cdot}\right) \text { radical scavenging activities of AMP extracts and VC was comparatively } \\
\text { analyzed and the result revealed that the antioxidant activity of AMP extracts was superior to VC. }\end{array}$ \\
\hline
\end{tabular}

\section{KEYWORDS}

Aronia melanocarpa, response surface methodology, ultrasound-assisted extraction, anthocyanin, antioxidant activity.

\section{INTRODUCTION}

AMP that can be used in food, beverage, jam, canned food, preserved fruit, fruit juice, fruit wine and so on, which is also named the wild cherry berry, belongs to the Rosaceae and is native to Canada and North America [1-2]. The fruits of AMP, round in shape and black-purple in color, are a kind of new berry with extremely high nutritional and economic value [3]. "Berry" is used for describing any small edible fruit, usually tender and juicy, fruity, seeds in the flesh, sweet and sour flavor and have different color intensity, which is rich in polyphenols, including anthocyanins, flavonoids and proanthocyanidins [4-5]. Anthocyanin is a kind of natural pigment widely exists in plants and have been reported to possess a multiple biological activity, including antioxidant, anti-cancer, anti-thrombosis, improving immunity and promoting erythrolabe synthesis and other biological activities, particularly antioxidant activity that is 4.4 times higher than ascorbic acid [6-7]. Anthocyanins have been widely used in food and medicine and other fields due to their unique functional properties.

Ultrasonic-assisted extraction can improve the extraction rate of heatsensitive biological active ingredients under rather low processing temperatures which is more effective than the conventional techniques of extraction [8-9]. The mechanical effect of ultrasound causes more solvents to penetrate into the tissue cells, then improve the mass transfer, and the breakage of the cell wall is favorable for the release of the tissue cell contents, which can reduces the processing time and the usage of solvents compared with the traditional extraction methods. Additionally, $\mathrm{O}^{2-}$. radical scavenging activity of AMP extracts is analyzed, and the antioxidant activity of AMP extracts is evaluated through in vitro antioxidant activity test [10-11].

\section{MATERIALS AND METHODS}

\subsection{Plant Material}

Aronia Melanocarpa named Fukangyuan NO.1 were purchased in Fukangyuan Technology Co., Ltd., Liaoning, China (the coordinate was $\left.40^{\circ} 47^{\prime} 41^{\prime \prime} \mathrm{N}, 122^{\circ} 40^{\prime} 42^{\prime \prime} \mathrm{E}\right)$. The berries were stored at $-80^{\circ} \mathrm{C}$ until required.

\subsection{Chemical Reagent}

All chemical reagents used in this study were analytical grade. Hydrochloric acid, anhydrous ethanol, sodium acetate anhydrous, potassium chloride, pyrogallol and all the other reagents were obtained from the reagent management office in Shenyang Agricultural University (Liaoning, Shenyang, China).

\subsection{Determination of Total Anthocyanins}

According to the structural characteristics of anthocyanins, the total anthocyanin content in the solution was calculated by the $\mathrm{pH}$-differential method [12-13]. $5 \mathrm{~g}$ of completely broken samples were extract with ethanol solution under certain conditions. $1 \mathrm{~mL}$ extract through the method of vacuum infiltration was taken and respectively added to $24 \mathrm{ml}$ of potassium chloride buffer $(\mathrm{pH}=1.0)$ and sodium acetate buffer $(\mathrm{pH}=4.5)$. The mixed liquid was placed at room temperature for $20 \mathrm{~min}$ to make the mixed liquid equilibrium, and the absorbance of $\mathrm{A}$ was measured at $520 \mathrm{~nm}$ and $700 \mathrm{~nm}$ with a UV-Vis spectrophotometer (TU-1810, PuXi, China), respectively, with distilled water as blank. The absorbance value $(\Delta \mathrm{A})$ of the diluted sample was computed according to the following formula:

$$
\Delta \mathrm{A}=\left(\mathrm{A}_{2520}-\mathrm{A}_{700}\right) \mathrm{pH}_{1.0}-\left(\mathrm{A}_{2520}-\mathrm{A}_{700}\right) \mathrm{pH}_{4.5}
$$

The total anthocyanins content expressed as mg cyanidin-3-glucoside equivalents per litre of extract, was computed according to the formula (1).

total anthocyanins content $\quad / \quad)=\frac{\Delta \mathrm{A} \times \mathrm{M} \times \mathrm{V} \times \mathrm{n}}{\varepsilon \times \mathrm{m}}$

Where $\Delta \mathrm{A}$ is absorbance,M (449.2) is cyanidin-3-glucoside molecular weight, $\mathrm{V}$ is total volume of extract, $\mathrm{n}$ is dilution ratio of extract, $\varepsilon$ (26900) is the molar absorbtivity, $\mathrm{m}$ is sample mass.

\section{$2.4 \quad$ Ultrasonic-assisted Extraction (UAE)}

The UAE was performed in an ultrasonic device (SB25-12DTN, Nibo Scientz biological technology co., LTD, China). Sample (5 g) was extracted with absolute ethanol under these various conditions: ethanol concentration ranging from 0 to $100 \%$, ultrasonic power from 0 to $200 \mathrm{~W}$, liquid-solid ratio from 5 to $30(\mathrm{~mL} / \mathrm{g})$, ultrasonic temperature from 0 to 60 ${ }^{\circ} \mathrm{C}$ and ultrasonic time from 10 to $60 \mathrm{~min}$. The total anthocyanin extracts 
were computed according to the formula (1).

\subsection{Experimental Design}

Based on the basis of single-factor experiment, according to the BoxBehnken center design method of Design - Expert software, the response surface analysis method of the four factors and three levels was designed to optimize the extraction of AMP anthocyanins in ultrasonic process, and the levels and the factors of experimental design were shown in Table 1 [14].

Table 1: Factors and levels of response surface design

\begin{tabular}{|c|c|c|c|c|}
\hline \multirow{2}{*}{ Level } & \multicolumn{3}{|c|}{ Factor } \\
\cline { 2 - 5 } & $\begin{array}{c}\text { A: Ethanol concentration } \\
(\%)\end{array}$ & $\begin{array}{c}\text { B: Ultrasonic power } \\
(\mathrm{W})\end{array}$ & $\begin{array}{c}\text { C: Liquid-solid ratio } \\
(\mathrm{ml} / \mathrm{g})\end{array}$ & $\begin{array}{c}\text { Dextraction time } \\
(\mathrm{min})\end{array}$ \\
\hline-1 & 40 & 120 & 15 & 40 \\
\hline 0 & 50 & 160 & 20 & 60 \\
\hline 1 & 60 & 200 & 25 & 80 \\
\hline
\end{tabular}

\subsection{Prepurification of Anthocyanins}

After the liquid was filtered by vacuum, the filtrate was concentrated by rotary evaporator at $40{ }^{\circ} \mathrm{C}$ (RE-5203A, Shanghai Bilon Instruments Co., Ltd., China). Then, the concentrated samples were filtered under vacuum condition, and separated by glass column with macroporous resin HP-20 [15]. Deionized water was used to remove water soluble substances, then $75 \%$ ethanol elution was used to elute anthocyanins. The eluent was completely removed ethanol by rotary evaporation and then freeze-dried into powder by vacuum freeze dryer (LGO.2, Shenyang Aerospace Xinyang Quick Freezing Equip. Manuf. Co., Ltd., China). Purified anthocyanin powder was stored at $4{ }^{\circ} \mathrm{C}$. The purity was increased from $1.75 \%$ to about $30.81 \%$.

\subsection{Antioxidant Activity Measurement}

$4.5 \mathrm{~mL}$ Tris- $\mathrm{HCl}(50 \mathrm{mM}, \mathrm{pH}=8.2)$ was added to a tube and heated up in a water bath for $25 \mathrm{~min}$ at $25^{\circ} \mathrm{C} .2 \mathrm{~mL}$ different concentrations of the sample solution were added to the tube and then $0.4 \mathrm{~mL}$ pyrogallol solution $(25$ $\mathrm{mM})$ using $\mathrm{HCl}(10 \mathrm{mM})$ as solvent. The mixed solution was shaken well successively, followed by reaction for $4 \mathrm{~min}, 2$ drops of $\mathrm{HCl}$ was added into the mixture to terminate the reaction. The ethanol solution with volume fraction of $80 \%$ was used as blank control and the absorbance was measured at $320 \mathrm{~nm} . \mathrm{O}^{2-\cdot}$ scavenging capacity was computed according to the formula (2).

$$
\mathrm{O}^{2-\cdot} \text { scavenging capacity }(\%)=\left[1-\left(\mathrm{A}_{1}-\mathrm{A}_{2}\right) / \mathrm{A}\right] \times 100 \%
$$

Where $A_{1}$ is the absorbance value of the system with sample solution and pyrogallol solution, $A_{2}$ is the absorbance value of the system without pyrogallol solution and $\mathrm{A}$ is the absorbance value of the system without sample solution.

\subsection{Statistical Analysis}

Each experiment was done in 3 groups of parallel and the data was expressed as the mean + standard deviation. The data of single factor and antioxidant experiments was analyzed by SPSS 16.0 (SPSS Inc., Chicago, IL, USA) and the response surface was analyzed by Design-expert. v8.0.5b [16].

\section{RESULTS AND DISCUSSION}

\subsection{Single-factor Experimental Analysis}

The effect of ethanol concentration on AMP yield was shown in Figure 1A. When the ethanol concentration was less than $60 \%$, AMP yield increased as the ethanol concentration increased. The reason was that the ethanol concentration increased, which led to the reduction of water-soluble pigment, such as polysaccharide and pectin, which inhibited the dissolution of anthocyanins. When the ethanol concentration was greater than $60 \%$, the polarity difference between anthocyanin and solvent was increased, and the dissolution of anthocyanins was inhibited. Therefore, the optimum ethanol concentration was $60 \%$. The effect of ultrasonic power on AMP yield was shown in Figure 1B. When the ultrasonic power is less than $160 \mathrm{~W}$, AMP yield increased as the ultrasonic power increased. Probably because the sample absorbed a large amount of solvent and expanded under the ultrasonic cavitation and mechanical action, so that the cell wall porosity was increased, and the cell wall and cell membrane were destroyed, and the anthocyanins were more easily dissolved. When the power was too high, the free anthocyanins were degraded under the mechanical action of ultrasound, at the same time not only the number of bubbles in the solvent were increased and the cavitation effect was reduced, but also AMP yield was affected. Therefore, the optimal ultrasonic power was $160 \mathrm{~W}$. The effect of liquid-solid ratio on AMP yield was shown in Figure 1C. When the liquid-solid ratio was less than 20 $(\mathrm{mL} / \mathrm{g})$, AMP yield increased as the liquid-solid ratio increased. It was possible that the solvent was so little that too easy to reach saturation and then anthocyanins were difficult to extract completely. When the liquidsolid ratio was more than $20(\mathrm{~mL} / \mathrm{g})$, AMP yield began to decrease as the liquid-solid ratio increased. The mass transfer process was accelerated because of the increase of the concentration difference. When the solvent was too much, the ultrasonic absorption of the samples was reduced and the impurities in the samples were dissolved, so that AMP yield was reduced, but also the burden of concentration was increased. Therefore, the best liquid-solid ratio was $20(\mathrm{~mL} / \mathrm{g})$. The effect of temperature on AMP yield was shown in Figure 1D. When the temperature was greater than $40^{\circ} \mathrm{C}$, AMP yield decreased gradually. Because the heat resistance of anthocyanins was relatively poor, the increase of tempering temperature would cause the structure of anthocyanins change and decreased AMP yield. Therefore, the best ultrasonic temperature was $40^{\circ} \mathrm{C}$. The effect of extraction time on AMP yield was shown in Figure 1E. When the ultrasonic time was greater than $50 \mathrm{~min}$, AMP yield decreased slowly. It was possible that the cell wall and cell membrane of the sample were completely broken under the action of ultrasound and the extension of ultrasonic time would lead to the degradation of some anthocyanins. Therefore, the optimal ultrasonic time was $50 \mathrm{~min}$ [17].
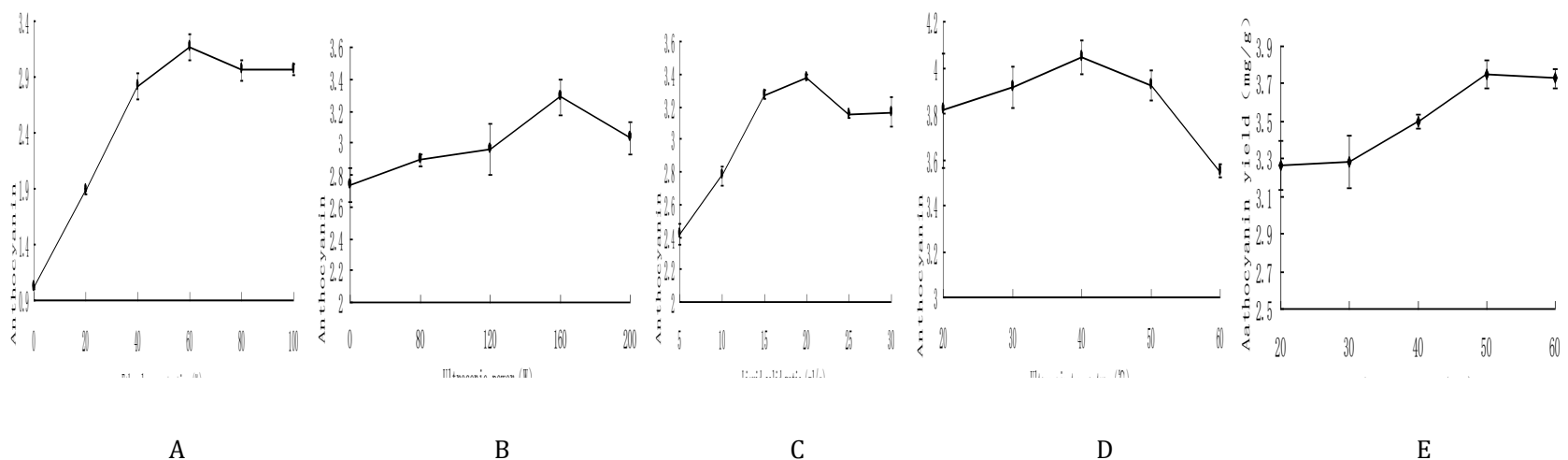

A

B

C

Figures 1: Effects of different extraction parameters on anthocyanin yield: (A) ethanol concentration, (\%); (B) ultrasonic power, (W); (C) liquid-solid ratio, $(\mathrm{mL} / \mathrm{g})$; (D) ultrasonic temperature, $\left({ }^{\circ} \mathrm{C}\right)$; (E) extraction time, $(\mathrm{min})$. 
3.2 Design and Results of Response Surface Experiment of Box Behnken

Table 2: Design and results of Box-Behnken experiments

\begin{tabular}{|c|c|c|c|c|c|}
\hline No. & A & B & C & D & $\begin{array}{c}\text { Y: Anthocyanin } \\
\text { yield(mg/g) }\end{array}$ \\
\hline 1 & -1 & -1 & 0 & 0 & 3.89 \\
\hline 2 & 1 & -1 & 0 & 0 & 3.917 \\
\hline 3 & -1 & 1 & 0 & 0 & 3.909 \\
\hline 4 & 1 & 1 & 0 & 0 & 4.049 \\
\hline 6 & 0 & 0 & 1 & -1 & 3.89 \\
\hline 7 & 0 & 0 & -1 & -1 & 3.856 \\
\hline 8 & 0 & 0 & 1 & -1 & 3.839 \\
\hline 9 & -1 & 0 & 0 & -1 & 3.856 \\
\hline 10 & 1 & 0 & 0 & -1 & 3.982 \\
\hline 11 & -1 & 0 & 0 & -1 & 3.839 \\
\hline 12 & 0 & 0 & 0 & -1 & 3.764 \\
\hline 13 & 0 & -1 & -1 & 0 & 4.065 \\
\hline 14 & 0 & 1 & -1 & 0 & 4.144 \\
\hline 15 & 0 & -1 & 1 & 0 & 4.016 \\
\hline 16 & 0 & 1 & 1 & 0 & 3.961 \\
\hline 17 & -1 & 0 & -1 & 0 & 3.892 \\
\hline 18 & 1 & 0 & -1 & 0 & 3.843 \\
\hline 19 & -1 & 0 & 1 & 0 & 3.503 \\
\hline 20 & 1 & 0 & 1 & 0 & 3.86 \\
\hline 21 & 0 & -1 & 0 & -1 & 4.04 \\
\hline 22 & 0 & 1 & 0 & -1 & 4.247 \\
\hline 23 & 0 & -1 & 0 & -1 & 4.065 \\
\hline 24 & 0 & 1 & 0 & -1 & 3.956 \\
\hline 25 & 0 & 0 & 0 & 0 & 4.29 \\
\hline 26 & 0 & 0 & 0 & 0 & 4.256 \\
\hline & & & & & \\
\hline
\end{tabular}

\begin{tabular}{|l|l|l|l|l|l|}
\hline 27 & 0 & 0 & 0 & 0 & 4.247 \\
\hline 28 & 0 & 0 & 0 & 0 & 4.297 \\
\hline 29 & 0 & 0 & 0 & 0 & 4.287 \\
\hline
\end{tabular}

According to the design theory of the response surface experiment of Box -Behnken, on the basis of single-factor experiment, 4 factors were selected at $40{ }^{\circ} \mathrm{C}$ that were ethanol concentration (A), ultrasonic power (B), liquidsolid ratio (C) and ultrasonic time (D). The response surface experiment of four factors and three levels was carried out with AMP yield as the response value [18]. There were 29 experimental points, including 24 factorial points and 5 null points and the experimental design and results were shown in Table 2.

\subsection{Model Establishment and Significance Test}

Design-expert. v8.0.5b was used to analyze the experimental datas and the two - order polynomial model of the four factors and of AMP yield was obtained by regression fitting. The model was as follows: $\mathrm{Y}=4.28+0.044 \mathrm{~A}+0.023 \mathrm{~B}-0.071 \mathrm{C}-0.068 \mathrm{D}+0.028 \mathrm{AB}+0.10 \mathrm{AC}-0.050 \mathrm{AD}-$

$0.033 B C-0.079 B D+0.053 C D-0.29 A^{2}-0.043 B^{2}-0.20 C^{2}-0.14 D 2$. Where $Y$ was the predictive value of AMP yield. From Table 3, the regression model was extremely significant $(\mathrm{p}<0.0001)$ and the lack of fit was not significant $(\mathrm{p}=$ $0.1210>0.05$ ), which shown that the experimental error was small. The results that $\mathrm{R}^{2}$ was $0.9804, \mathrm{R}^{2}$ adj was 0.9607 and $\mathrm{R}^{2}$ pred was 0.8955 shown that the model had a good fitting degree, which could explain the change of the $96.07 \%$ of response value and the independent variable have a significant linear relationship with the response value and be used to predict the response under different variables. Variance analysis showed that the factor of $A$ and $C$ and $D$ had extremely significant effect $(p<0.01)$ In this model, the effects of various factors on AMP yield were as follows: liquid-solid ratio $(\mathrm{C})>$ eultrasonic time $(\mathrm{D})>$ thanol concentration $(\mathrm{A})>$ ultrasonic power $(\mathrm{B})$.

Table 3: Variance analysis for four elements quadratic regression model

\begin{tabular}{|c|c|c|c|c|c|c|}
\hline Source & Sum of Squares & $\mathrm{df}$ & $\begin{array}{c}\text { Mean } \\
\text { Square }\end{array}$ & $\begin{array}{c}\mathrm{F} \\
\text { value }\end{array}$ & $\begin{array}{l}\text { P-value } \\
\text { Prob }>F\end{array}$ & significance \\
\hline Model & 0.97 & 14 & 0.069 & 49.96 & $<0.0001$ & $* *$ \\
\hline $\mathrm{A}$ & 0.023 & 1 & 0.023 & 16.71 & 0.0011 & $* *$ \\
\hline $\mathrm{B}$ & $6.211 \mathrm{E}-003$ & 1 & $6.211 \mathrm{E}-003$ & 4.50 & 0.0522 & $* *$ \\
\hline $\mathrm{C}$ & 0.060 & 1 & 0.060 & 43.63 & $<0.0001$ & $*$ \\
\hline $\mathrm{D}$ & 0.055 & 1 & 0.055 & 40.11 & $<0.0001$ & $* *$ \\
\hline $\mathrm{AB}$ & $3.192 \mathrm{E}-003$ & 1 & 3.192E-003 & 2.31 & 0.1505 & $* *$ \\
\hline $\mathrm{AC}$ & 0.041 & 1 & 0.041 & 29.86 & $<0.0001$ & $* *$ \\
\hline $\mathrm{AD}$ & 0.010 & 1 & 0.010 & 7.32 & 0.0171 & $* *$ \\
\hline $\mathrm{BC}$ & $4.489 \mathrm{E}-003$ & 1 & $4.489 \mathrm{E}-003$ & 3.25 & 0.0928 & $*$ \\
\hline $\mathrm{BD}$ & 0.025 & 1 & 0.025 & 18.09 & 0.0128 & $* *$ \\
\hline CD & 0.011 & 1 & 0.011 & 8.14 & 0.0931 & \\
\hline $\mathrm{A}^{2}$ & 0.54 & 1 & 0.54 & 387.94 & $<0.0001$ & $* *$ \\
\hline $\mathrm{B}^{2}$ & 0.012 & 1 & 0.012 & 8.65 & 0.0107 & $* *$ \\
\hline $\mathrm{C}^{2}$ & 0.26 & 1 & 0.26 & 191.39 & $<0.0001$ & $* *$ \\
\hline $\mathrm{D}^{2}$ & 0.13 & 1 & 0.13 & 97.01 & $<0.0001$ & $* *$ \\
\hline Residual & 0.019 & 14 & $1.380 \mathrm{E}-003$ & & & \\
\hline Lack of Fit & 0.017 & 10 & $1.732 \mathrm{E}-003$ & 3.47 & 0.1210 & \\
\hline Pure Error & $1.997 \mathrm{E}-003$ & 4 & 4.993E-004 & & & \\
\hline Cor Total & 0.98 & 28 & & & & \\
\hline $\mathrm{R}^{2}$ & 0.9804 & & & & & \\
\hline R2 adj & 0.9607 & & & & & \\
\hline R2 pred & 0.8955 & & & & & \\
\hline
\end{tabular}

\subsection{Optimization and Verification of Response Surface Conditions}

From the results, the interactive effects of $A C, A D, B D$ and $C D$ were extremely significant, the response surface plots were shown in figure 2 . The figure 2 shown the interactive effects of the factors that were ethanol concentration, ultrasonic power, liquid-solid ratio and ultrasonic time on the amount of anthocyanins extraction from Aronia melanocarpa berries. Through analyzing the equation, the optimum extraction conditions were as follows: ethanol concentration was $62.41 \%$, ultrasonic power was 198.04 W, liquid-solid ratio was $18.50(\mathrm{~mL} / \mathrm{g})$ and ultrasonic time was $44.25 \mathrm{~min}$ [19]. At this time, the most theoretical value of anthocyanins was $4.31893(\mathrm{mg} / \mathrm{g})$. Taking into account the feasibility of the actual operation, the process parameters were adjusted as follows: ethanol concentration was $62 \%$, ultrasonic power was $198 \mathrm{~W}$, liquid-solid ratio was $19(\mathrm{~mL} / \mathrm{g})$ and ultrasonic time was $44 \mathrm{~min}$ [20]. Under the optimal conditions, 3 parallel confirmatory experiments were performed and AMP yield was $4.248(\mathrm{mg} / \mathrm{g})$. The relative error between the actual value and the predicted value is about $1.67 \%$, which proves the validity of the model and has practical value [21].
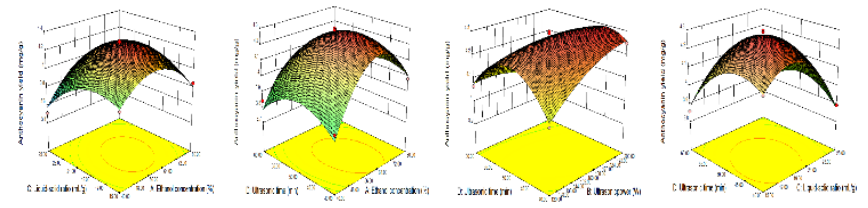

Figure 2: Response surface and contour plots showing the effects of different extraction parameters on anthocyanin yield

\subsection{2-- Scavenging Capacity}

02-- that was produced in the metabolism of organisms could cause mutation and necrosis of protein, polysaccharide and nucleic acid and even led to organismic oxygen poisoning [22]. The pyrogallol caused autooxidation in the alkaline environment and produced $02-\cdot$. The intermediate product had strong absorption in the UV region and AMP had inhibitory effect on auto-oxidation of the pyrogallol that reflected the strong 02-- scavenging capacity [23]. It can be seen from Figure 3 that $02-$ - scavenging percentages of AMP was on the rise with the increase of the mass concentration. When the concentration was in the range of 100-300 $\mathrm{g} / \mathrm{mL}, 02-\cdot$ scavenging percentages of AMP was higher than that of VC. 
When the concentration was more than $100-300 \mathrm{~g} / \mathrm{mL}$, the growth rate of 02-- scavenging percentages of AMP slowed down, less than VC. The regression equation of 02--scavenging capacity of AMP is: $\mathrm{Y}=36.364+0.104 \mathrm{X} \quad(\mathrm{R} 2=0.961)$, and the regression equation of $\mathrm{O2}-$ scavenging capacity of $\mathrm{VC}$ is $: \mathrm{Y}=4.282+0.187 \mathrm{X}(\mathrm{R} 2=0.958)$. When the AMP concentration was $131 \mathrm{~g} / \mathrm{mL}, 02-\cdot$ scavenging percentages reached $50 \%$. In conclusion, AMP extracts in this system showed good 02-• scavenging capacity.

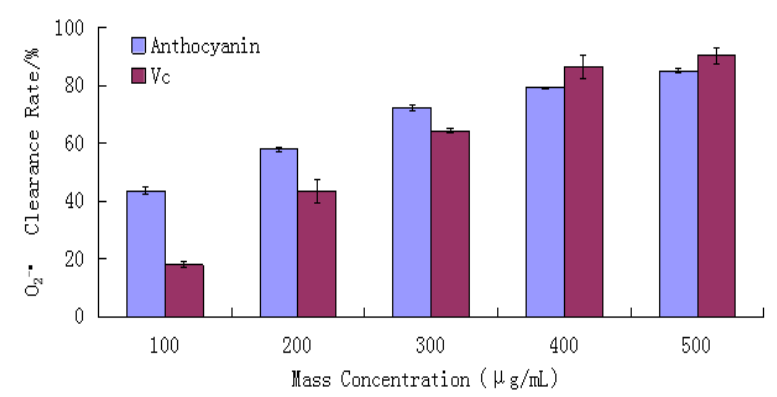

Figure 3: 02-• scavenging activity of Aronia melanocarpa anthocyanins (AMP) and VC

\section{CONCLUSION}

According to the design theory of the response surface experiment of Box -Behnken, on the basis of single-factor experiment, 4 factors were selected at $40{ }^{\circ} \mathrm{C}$ that were ethanol concentration (A), ultrasonic power (B), liquidsolid ratio (C) and ultrasonic time (D). The response surface experiment of four factors and three levels was carried out with AMP anthocyanin yield as the response value. Design-expert. v8.0.5b was used to analyze the experimental datas and the two - order polynomial model of the four factors and of AMP anthocyanin yield was obtained by regression fitting. Taking into account the feasibility of the actual operation, the process parameters were adjusted as follows: ethanol concentration was $62 \%$, ultrasonic power was $198 \mathrm{~W}$, liquid-solid ratio was 19 (mL/g) and ultrasonic time was $44 \mathrm{~min}$. Under the optimal conditions, 3 parallel confirmatory experiments were performed, and AMP anthocyanin yield was $4.248(\mathrm{mg} / \mathrm{g})$. The relative error between the actual value and the predicted value is about $1.67 \%$, which proves the validity of the model and has practical value. In the experiment of $02-\cdot$ scavenging activity, in a certain range of concentration $(100-300 \mathrm{~g} / \mathrm{mL})$, the antioxidant activity of AMP extracts scavenging activity was than VC.

\section{CONFLICT OF INTEREST}

The authors declare that there are no conflicts of interest.

\section{ACKNOWLEGEMENT}

The supports from the Ministry of Agriculture Special Public Welfare Industry (201303073-04).

\section{REFERENCES}

[1] Yu, X., Hu, W., Jiang, A., Chen, Y., Liu, X. 2016. Research progress of nutrient elements and the efficacy of Aronia melanocarpa. Journal of Food Science and Technology, 37, 396-400.

[2] Miebach, E.M., Adamiuk, M., Behsnilian, D. 2012. Stability of chokeberry bioactive polyphenols during juice processing and stabilization of a polyphenol-rich material from the by-product. Journal of Agricultural and Food Chemistry, 2, 244-258.

[3] Li, B., Gao, N.X., Lu, H., Meng, X., Zhang, Q., Jiao, X., Li, E., Chou, S., Zhang, Y., Chen, S. 2016. Macroporous adsorption resin for the purification of polyphenols from Aroma melanocarpa berries. Journal of Food Science, 37, 69-74.

[4] Veberic, R., Slatnar, A., Bizjak, J., Stampar, F. Petkovsek, M.M. 2015. Anthocyanin composition of different wild and cultivated berry species. LWT- Food Science and Technology, 60, 509-517.

[5] Kim, B., Chai, S.K., Pham, T.X., Park, Y., Martin, D.A., Xie, L., Taheri, R., Lee, J., Bolling, B.W. 2013. Aronia melanocarpa, (chokeberry) polyphenolrich extract improves antioxidant function and reduces total plasma cholesterol in apolipoprotein E knockout mice. Journal of Nutrition Science Research, 33, 406-413.
[6] Risti, A.K., Šavikin, K., Zduni, G. 2011. Biological activity and chemical composition of different berry juices. Journal Food Chemistry, 125, 1412 1417.

[7] Brzóska, M.M., Rogalska, J., Sidorczuk, M.G., Jurczuk, M., Roszczenko, A., Tomczyk, M. 2015. Protective effect of Aronia melanocarpa polyphenols against cadmium-induced disorders in bone metabolism: a study in a rat model of lifetime human exposure to this heavy metal. Chemico-Biological Interactions, 229, 132-146.

[8] Tao, Y., Zhang, Z., Sun, D.W. 2014. Kinetic modeling of ultrasoundassisted extraction of phenolic compounds from grape marc: influence of acoustic energy density and temperature. Journal Ultrasonics Sonochemistry, 21, 1461-1469.

[9] He, B., Zhang, L.L., Yue, X.Y., Liang, J., Jiang, J., Gao, X.L., Yue, P.X. 2016. Optimization of ultrasound-assisted extraction of phenolic compounds and anthocyanins from blueberry (Vaccinium ashei) wine pomace. Journal Food Chemistry, 204, 70-76.

[10] Li, M.S. 2014. Optimization of ultrasonic extraction technology of anthocyanins from Aornia melanoearpa Elliot by response surface method. Journal China Brewing, 33, 117-121.

[11] Cnen, G., Huang, L.S., Xu, J., Jian, S.P., Wang, H.L. 2012. UltrasonicAssisted Extraction and Antioxidant Activity of Antho Cyanins from Blackberry Fruits. Journal Food Science, 33, 283-289.

[12] Song, D., Meng, X., Wang, C., Wang, G., Lü, C. 2013. Determination of blueberry anthocyanins through $\mathrm{pH}$ differential method. Journal of Shenyang Agricultural University, 44, 231-233.

[13] Denev, P., Kratchanova, M., Ciz, M., Lojek, A., Vasicek, O., Nedelcheva, P., Blazheva, D, Toshkova, R., Gardeva, E., Yossifova, L., Hyrsl, P., Vojtek, L. 2014. Biological activities of selected polyphenol-rich fruits related to immunity and gastrointestinal health. Journal Food Chemistry, 15 (157), $37-44$.

[14] Li, Y., Zhang, M., Ma, C., Li, Z., Li, X. 2015. Optimization of ultrasoundassisted extraction of polyphenols from blueberry leaves by aesponse surface method. Journal Science and Technology of Food Industry, 36, 234238.

[15] Guo, S.L., Zhu, F.M., Wang, N. 2015. Study of resin purification technology and stability of anthocyanins from Aronia melanocarpa berry. Journal Natural Product Research and Development, 9, 1636-1642.

[16] An, X., Wang, Y., Meng, X. 2016. Identification and comparative analysis of antioxidant ability of anthocyanins in Lonicera caerulea berry extracts. Journal Food Science, 37, 82-87.

[17] Zhu, L., Dong, F., Feng, X., Wang, J., Du, Y., Cheng, C. 2015. Comparative antioxidant activities of anthocyanins extracted from purple sweet potato by organic solvent ultrasonic-assisted and microwaveassisted extraction. Journal Food Science, 36, 83-88.

[18] Wang, J., Wang, Z., Wu, N., Chen, X., Liu, W., Min, Y. 2015. Study on extraction process of polysaccharide of russula virescens optimized by response surface methodology. Journal the Food Industry, 2, 181-184.

[19] Wang, Y., Li, B., Meng, X., An, X., MA, Y., Zhang, Q., Li, L., Li, D. Effect of in vitro simulated digestion on anthocyanin composition and antioxidant activity of Lonicera caerulea berry extracts. Journal Food Science, 37, 100105.

[20] Han, L., Suo, Y., Yang, Y., Meng, J., Hu, N. 2015. Optimization, characterization, and biological activity of polysaccharides from Berberis dasystachya Maxim. International Journal of Biological Macromolecules, 85, 655-666.

[21] Jeddou, K.B., Chaari, F., Maktouf, S., Ellouzc, O.N., Helbertd, C.B., Ghorbel, R.E. 2016. Structural, functional, and antioxidant properties of water-soluble polysaccharides from potatoes peels. Journal Food Chemistry, 205, 97.

[22] Wang, H., Liu, F., Xu, C., Lin, Y., Li, H., Shao, X. 2012. Alkali-extraction and antioxidant activity of total flavonoid from Sedum aizoon L. Journal Transactions of the Chinese Society of Agricultural Engineering, 28, 317321.

[23] Zi, M., Wang, Q., Wen, Q. 2009. Study of the spectral properties and antioxidant activities of purple sweet potato anthocyanins. Journal Modern Food Science and Technology, 25 (11), 1279-1281. 